\title{
Treatment of midfacial hypoplasia in syndromic and cleft lip and palate patients by means of a rigid external distractor (RED)
}

Eduardo Franzotti Sant'Anna¹, Adriana de Alcantara Cury-Saramago², Geórgia Wain Thi Lau³, John W. Polley4, Álvaro A. Figueroa ${ }^{4}$

Introduction: Distraction Osteogenesis (DO) became an alternative for the treatment of severe craniofacial skeletal dysplasias. The rigid external distraction device (RED) is successfully used to advance the maxilla and all the maxillary-orbital-frontal complex (monobloc) in children, adolescents and adults. This approach provides predictable and stable results, and it can be applied alone or with craniofacial orthognathic surgical procedures. Objective: In the present article, the technical aspects relevant to an adequate application of the RED will be described, including the planning, surgical and orthodontic procedures.

Keywords: Distraction. Maxilla. Midface.

Introdução: a Distração Osteogênica (DO) tornou-se uma alternativa para o tratamento das displasias craniofaciais esqueléticas severas. $\mathrm{O}$ aparelho distrator externo rígido (RED) é utilizado com êxito para avançar a maxila e todo o complexo maxilar-orbital-frontal (monobloco) em crianças, adolescentes e adultos. Essa abordagem proporciona resultados previsíveis e estáveis, podendo ser aplicada isoladamente ou junto a procedimentos cirúrgicos ortognáticos craniofaciais. Objetivo: no presente artigo, serão descritos os aspectos técnicos pertinentes a uma adequada aplicação do RED, incluindo o planejamento, procedimentos cirúrgicos e ortodônticos.

Palavras-chave: Distração. Maxila. Face média.

${ }^{1}$ Associate Professor of Orthodontics, Pediatric Dentistry and Orthodontics Department, School of Dentistry of the Federal University of Rio de Janeiro.

${ }^{2}$ Adjunct Professor of the Graduation, Specialization and MSc Course in Orthodontics of the Fluminense Federal University.

${ }^{3} \mathrm{PhD}$ Student of the Post-Graduation Course in Orthodontics, School of Dentistry of the Federal University of Rio de Janeiro.

${ }^{4}$ Co-director of the Rush Craniofacial Center, Department of Plastic and Reconstructive Surgery, no Rush University Medical Center, Chicago, IL.
How to cite this article: Sant'Anna EF, Cury-Saramago AA, Lau GWT, Polley JW, Figueroa AA. Treatment of midfacial hypoplasia in syndromic and cleft lip and palate patients by means of a rigid external distractor (RED). Dental Press J Orthod. 2013 July-Aug;18(4):134-43.

Submitted: May 31, 2013 - Revised and accepted: June 5, 2013

» The authors report no commercial, proprietary or financial interest in the products or companies described in this article.

» Patients displayed in this article previously approved the use of their facial and intraoral photographs.

Contact address: Eduardo Franzotti Sant'Anna

E-mail: eduardofranzotti@ortodontia.ufrj.br 


\section{INTRODUCTION}

Distraction osteogenesis (DO) has been used in the last decades to treat midface hypoplasia, for promoting its significant advancement (by means of a process of gradual stretch of the facial bones), when compared to the advancement at once, through the conventional orthognathic surgery or the monobloc surgery.

DO can be the treatment of choice for patients with Crouzon syndrome or Apert syndrome; $;^{8,17,23,30}$ hemifacial macrosomia; ${ }^{19}$ and mandibulofacial dysostosis, also known as Treacher Collins syndrome. Its successful application benefits patients with secondary severe maxillary hypoplasia and orofacial clefts; ${ }^{11,12,14,21,22}$ newborns presenting obstructive respiratory problems, as the occurred in patients with Pierre Robin sequence; ${ }^{3,4}$ and patients presenting large bone defect resulting from the resection of tumors or from trauma.

Molina et $\mathrm{al}^{18}$ were the pioneers on the use of DO for maxillary advancement, after incomplete horizontal osteotomy of the maxilla, with the aid of application of reverse traction by means of face mask and rubber bands.

The results of these first treatments motivated the development of alternative treatments and the formulation of new distractors with different designs - including the rigid external distraction device (RED).

\section{TECHNIQUE PRESENTATION}

\section{DO for maxillary advancement Device}

The device used to perform the distraction osteogenesis is composed of a rigid external structure, described on Figure 1A, and of an intraoral splint (Fig 1B), which will be connected with surgical wires (0.018-in) to the distractor screws, assembled between the vertical rod and the horizontal bars. ${ }^{12}$

Two medial rectangular tubes, welded to the anterior portion of the buccal arch of the splint (0.051-in), are used to anchor the connector hooks of the splint, which will be installed, in the doctor's office, after surgery - along with the carbon fiber anterior vertical rod, the distractor screws and the horizontal bars (Fig 1C). Besides, during surgery, the anterior part of the splint is fixed to the skeletal anchorage screws, bilaterally, between the canines and the upper lateral incisors (Fig 2A). This avoids the downward movement of the device during the distraction process and makes it quite rigid, adding stability to the splint. ${ }^{9}$
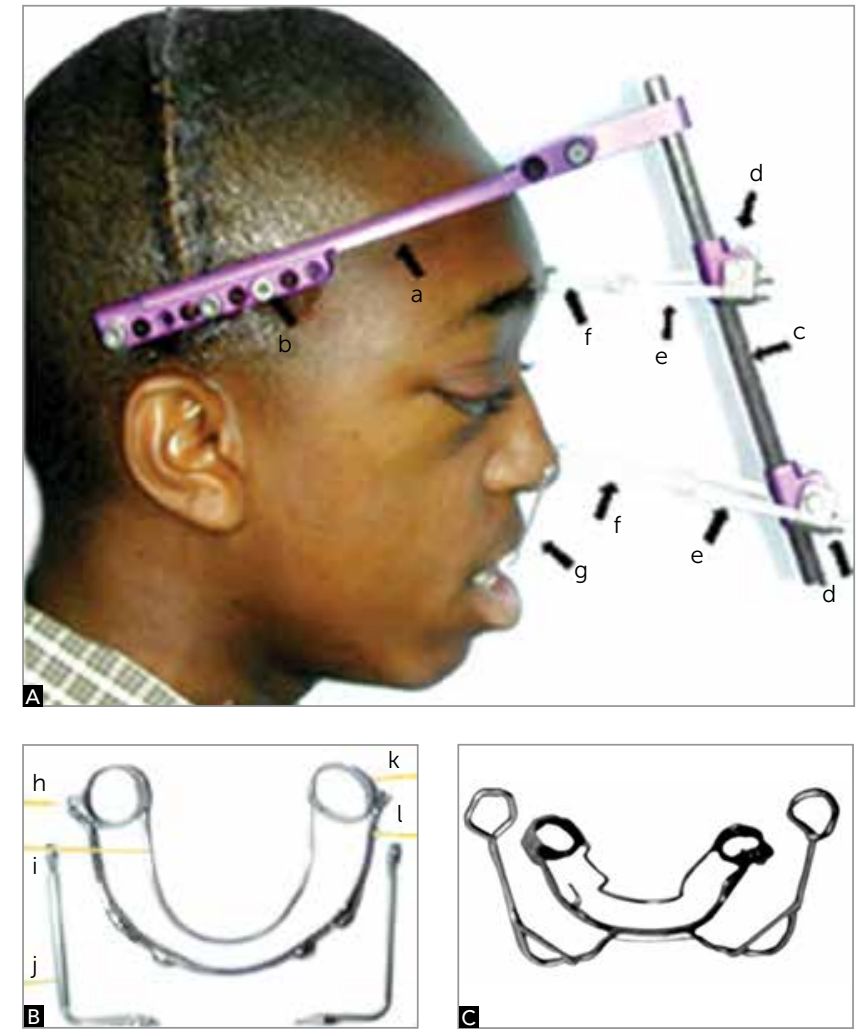

Figure 1 - A) Rigid external distraction device components: (a) cranial external halo; (b) fixation titanium screws, with active part of $45 \mathrm{~mm}$; (c) carbon fiber anterior vertical rod; (d) distractor screws; (e) horizontal bars; (f) surgica steel wires (0.018-in); (g) external hooks connected to the intraoral splint B) Intraoral splint composed of a buccal arch (0.051-in) + weld (h); a palatine arch, similar to a lingual arch (0.036-in) (i); external hook 0.051-in (j); orthodontic band (k) and buccal arch 0.051-in (I). C) Splint made from prefabricated extraoral arch of 0.051-in

\section{Surgery}

The protocol for maxillary DO treatment with this external distraction device may or may not include presurgical orthodontic dental alignment, depending on the evolutionary stage of the dentition of the patient with maxillary hypoplasia and severe facial cleft. The making of the intraoral splint is mandatory, being fixed to the teeth in a clinical appointment which will leave the patient ready for surgery - because the splint provides a point of anchorage for the maxillary advancement, and the other structures allow the connection between the dentition and the external halo.

The beginning of surgery is characterized by the installation of mini-implants between the root apexes of the lateral incisor and upper canines on both sides, followed by the connection to the splint, with surgical steel wire, which adds security to intraoral stability (Fig 2A). Then, a complete Le Fort I osteotomy is performed, with pterygomaxillary disjunction. 

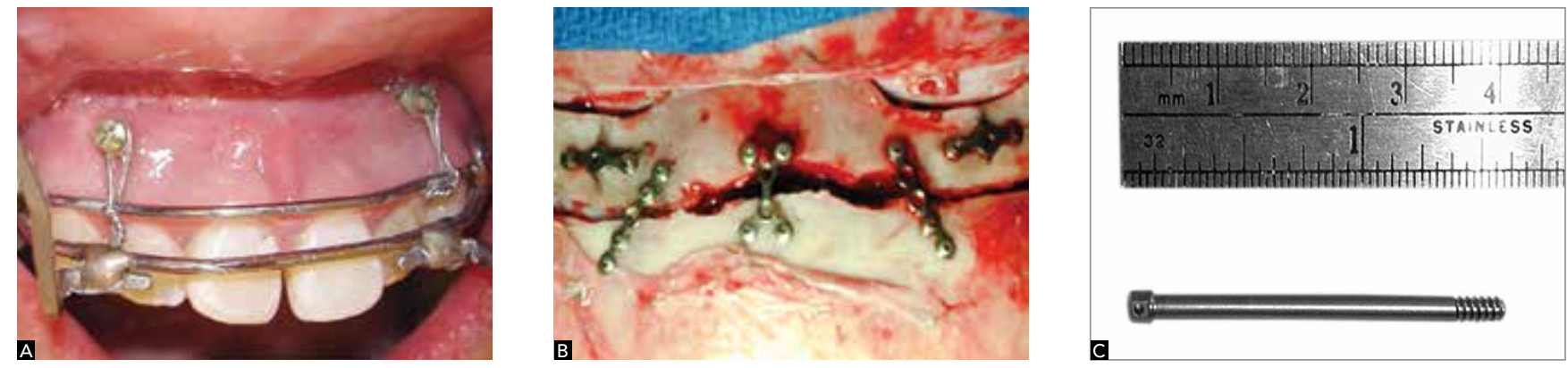

Figure 2 - A) Intraoral splint fixed with mini implants bilaterally installed between lateral incisors and canines. B) Rigid fixation, with titanium plates, of the frontal bone to the supraorbital protuberances. C) Upper traction pin, which is set to the lateral titanium plate, on the frontal bone. (B, C - Source: Figueroa, Polley, ${ }^{9}$ 2007).
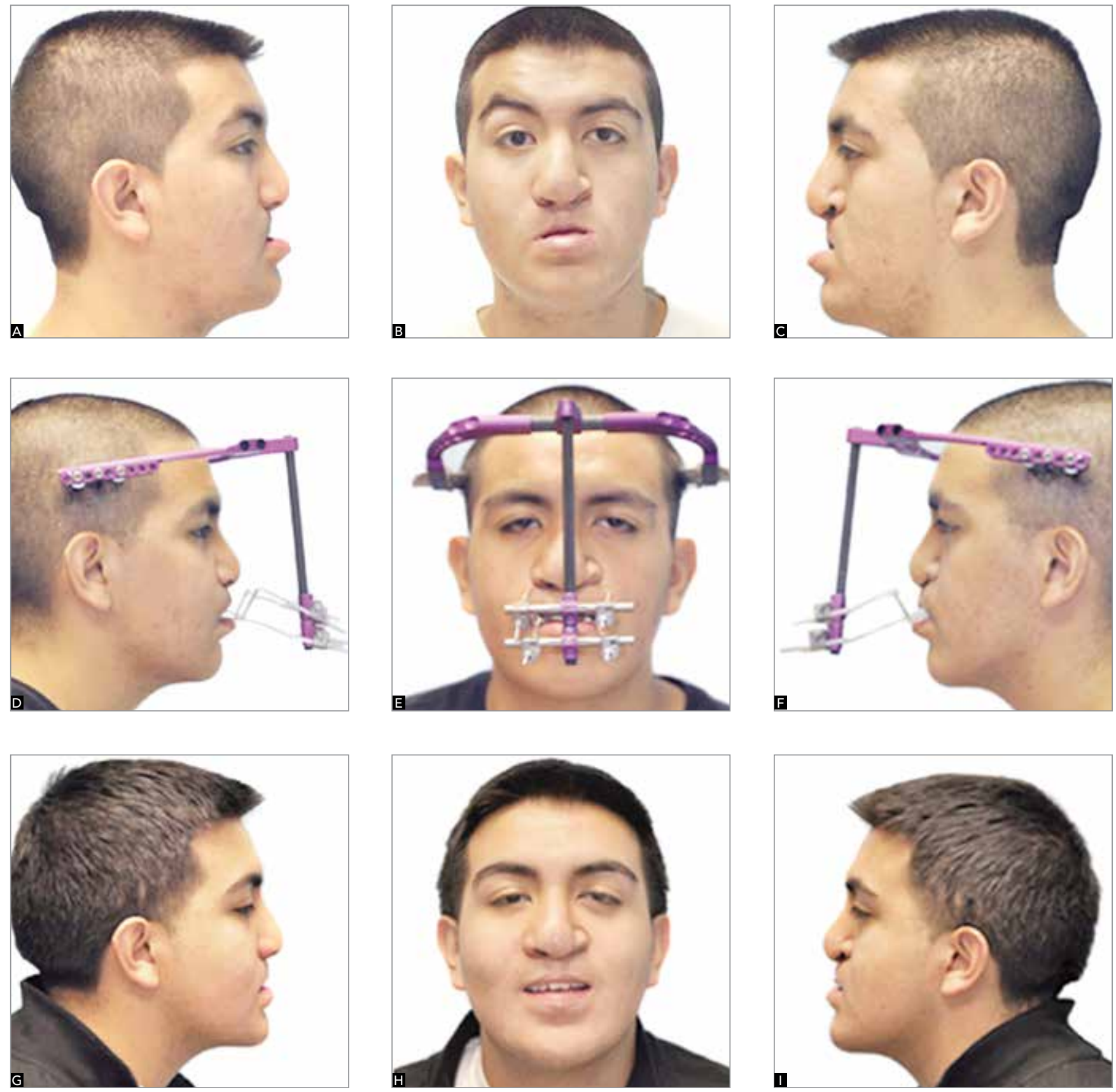

Figure 3 - A B B, C) Initial facial photographs of an adolescent with maxillary hypoplasia associated to cleft lip and palate. D, E, F) Patient with rigid external distractor device installed, after Le Fort I osteotomy. G, H, I) Final photographs: Maxillary advancement providing better maxillomandibular relation. 
The maxilla is not fractured and displaced downward, as frequently seen in the conventional orthognathic surgery. However, the surgeon must make sure of the complete mobility of the maxillary bone. There is the option of including the base of the malar bones and, also, the lateral aspect of the nasal bones during the osteotomy, which allows a significant advancement of the nasal and infraorbital regions (Fig 2B). The external halo is securely fixed to the skull, using specific titanium cranial pins. The correct positioning of the pins is imperative (Figs 1A and 1B) on the thicker part between the temporal and parietal bones - generally from 3 to $6 \mathrm{~cm}$ above the ear lobe -, in parallel or a little tilted upward in relation to Frankfurt's Horizontal Plane.
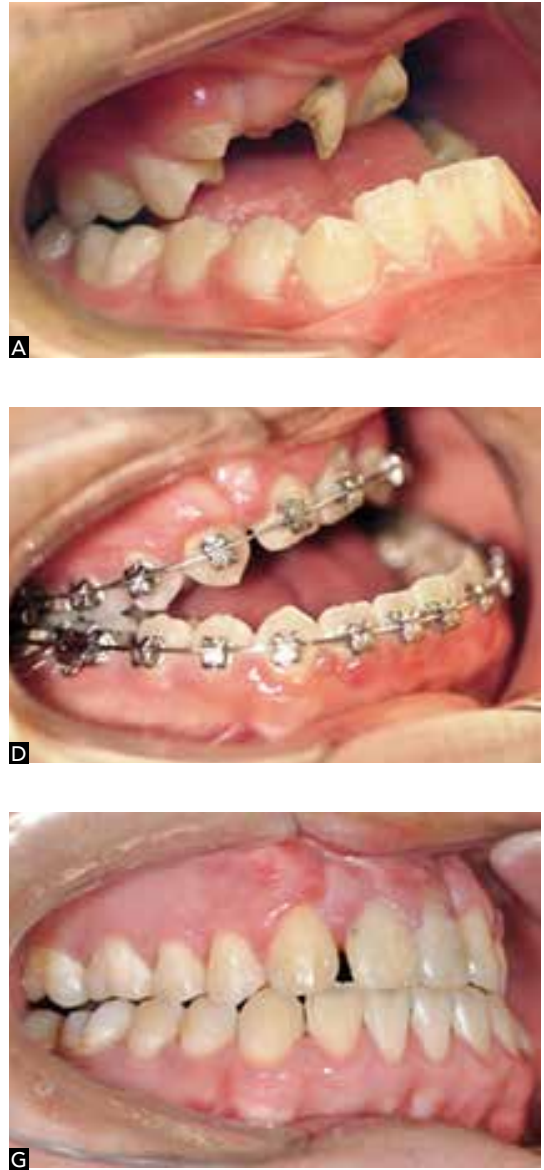
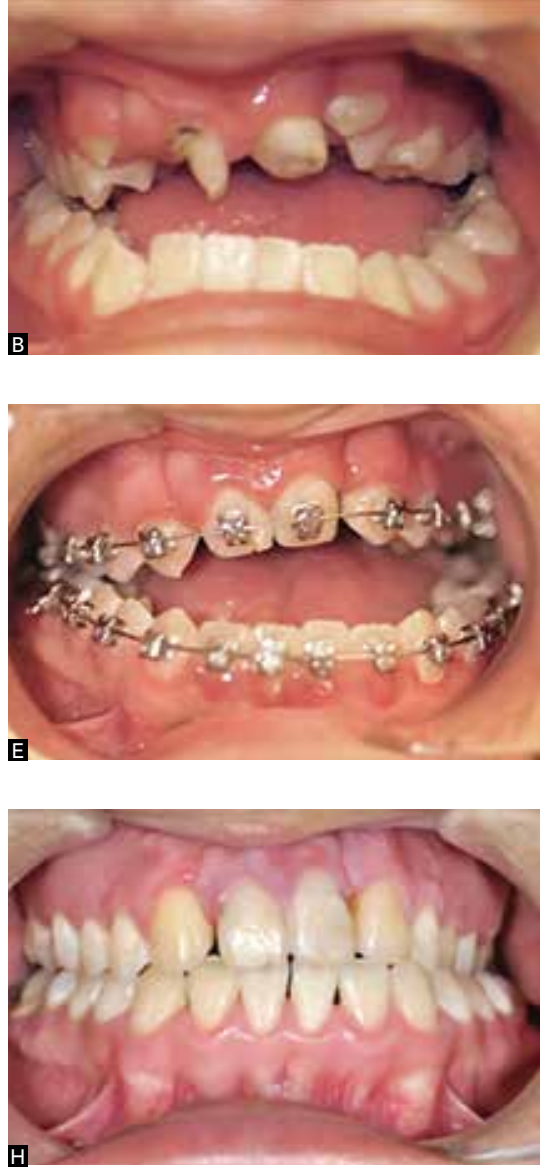
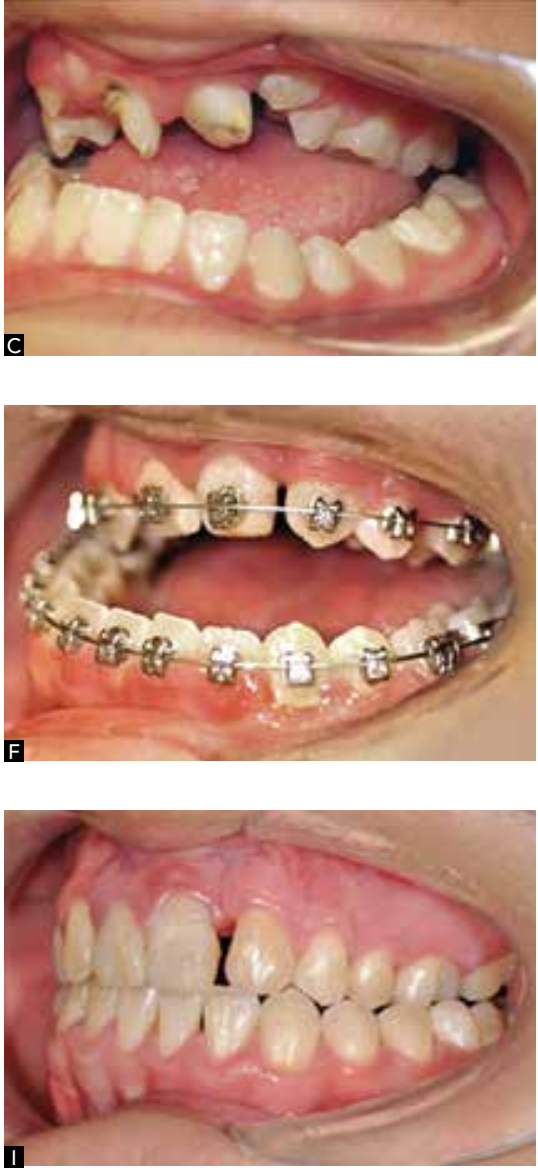

Figure 4 - Intraoral photographs of the patient presented on Figure 3: Initial images (A, B, C); pre-surgical orthodontic preparation (D, E, F) and finished treatment, after maxillary advancement with RED and Le Fort I orthognathic surgery $(\mathbf{G}, \mathbf{H}, \mathbf{I})$
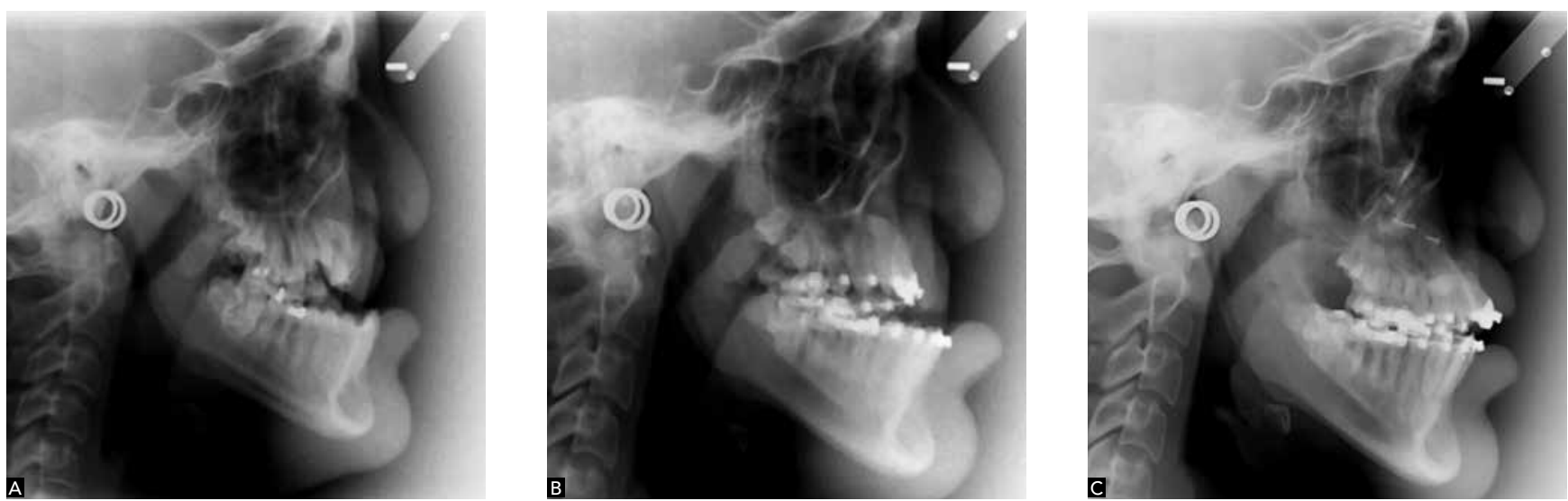

Figure 5 - Lateral cephalograms for monitoring the maxillary advancement of the patient of Figures 3 and 4 : A) initial radiograph; B) radiograph illustrating the pre-surgical orthodontic preparation; C) radiograph after maxillary advancement with RED. 
The anterior vertical rod, the distractor screws and the horizontal bars will only be installed between 3 and 7 days after the surgery (latency period), without discomfort for the patient and in clinical environment. When installed, the vertical rod is anteriorly moved away from the face, from 3 to $5 \mathrm{~cm}$, positioned on the midline and in parallel, or divergent in relation to the inferior region of the facial plane (Figs 3D, E and F).
The diet for the first post-surgical 24 hours is liquids and, then, soft foods are incorporated.

\section{Protocol}

The distraction protocol follows a rhythm of activation between 1 and $2 \mathrm{~mm} /$ day, depending on the severity of the condition and age of the patient (in young patients, there might not be a latency period
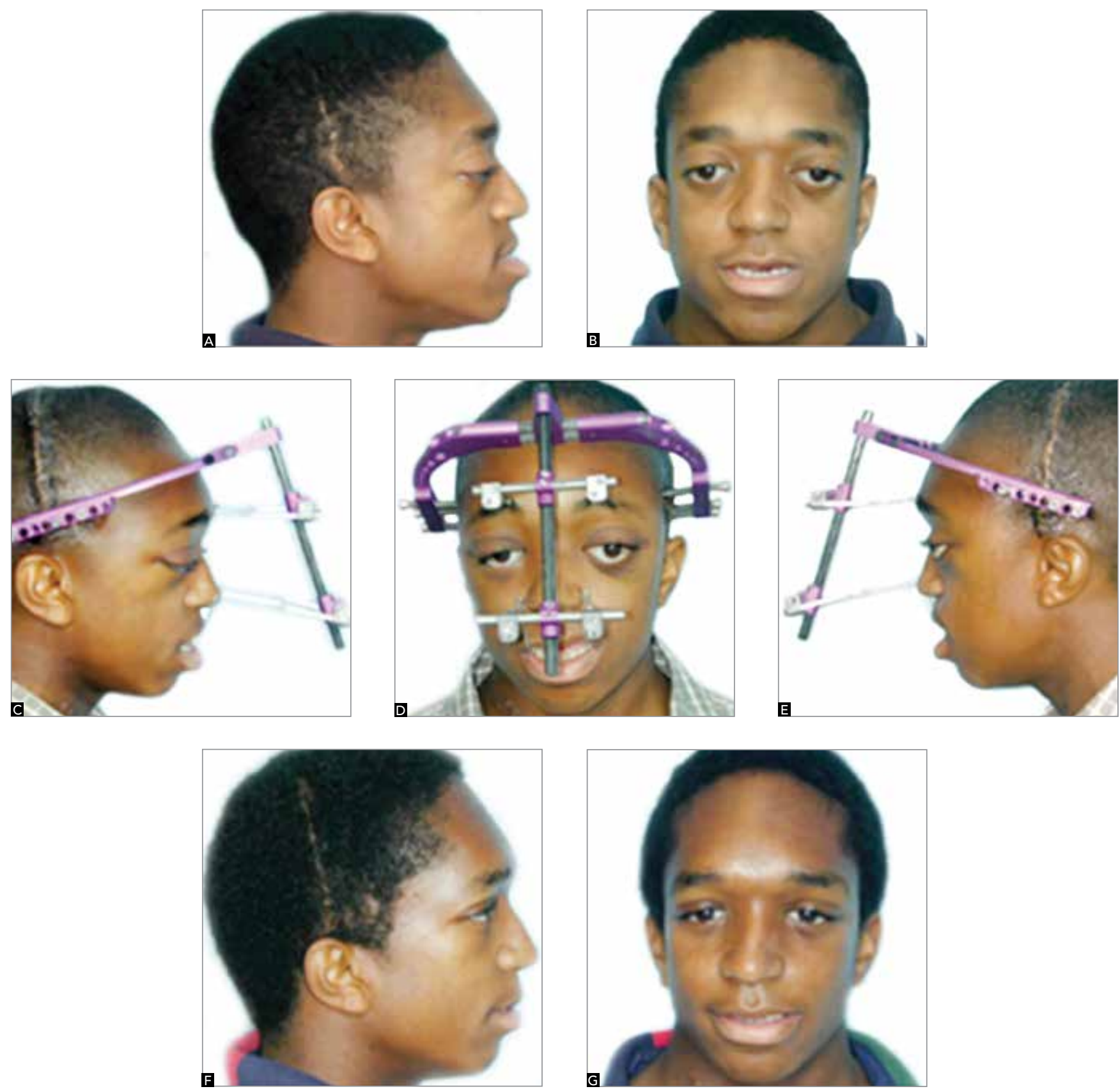

Figure 6 - A, B) Adolescent with Crouzon syndrome, maxillary and midface hypoplasia. C, D, E) Facial photographs after restorative surgery during childhood. Rigid external distraction device installed, after osteotomy for advancement in monobloc. (F, G) Final photographs, with remarkable improvement on the facial harmony, due to advancement of the maxilla and of the midface. 
and the rhythm may be faster). A period of about one or two weeks of distraction is enough for the correction in most patients, when the bone consolidation phase is initiated, which is between 4 and 8 weeks (Figs 3, 4 and 5). There are occasions in which a resistance to the maxillary advancement appears, at the end of the active phase of distraction. In these situations, the assemblage of a second distractor system on the vertical rod is chosen. In this way, a traction system is provided with two distractor systems, each one presenting two screws for activation (left and right side), significantly stronger and capable of overcoming any resistance offered by the soft tissues.

On patients in which an extreme maxillary advancement is planned, the clinician might notice the mobility of the maxillary bone in up to 12 weeks after removal of the external halo. Should the maxillary mobility cause discomfort, the surgeon might decide for the rigid fixation plates, to increase the stability of the maxillary bone. It is worth emphasizing that on patients in which there is insufficient consolidation of the maxilla, there is bone mobility on the vertical and transverse planes, and practically no tendency of anterior or posterior movement.

\section{Retention}

After maxillary consolidation, the external halo, the horizontal bars, the distractor screws and the surgical wires are removed in a clinical environment. Often, it is unnecessary to anesthetize adolescent and adult patients, unlike what occurs in children, in which removal is recommended under anesthesia in the surgical room and under mild sedation. Then, the external hooks of the intraoral splint are removed and the patient is oriented to use the Petit face mask during the night, promoting an active retention. The mask is used with rubber bands, through which a 400 to $500 \mathrm{gf}$ load is exerted for 6 to 8 weeks, until the stability of the maxilla in its new position is clinically verified, being possible to remove the intraoral splint and start or restart the orthodontic treatment.

\section{DO for midface advancement in monobloc}

In cases of patients with severe craniofacial syndromes, involving important frontal, orbital and maxillary deficiencies, the use of the rigid external distraction device also promotes improvement of this condition (Figs 6 and 7). The midface advancement in monobloc technique follows steps similar to those
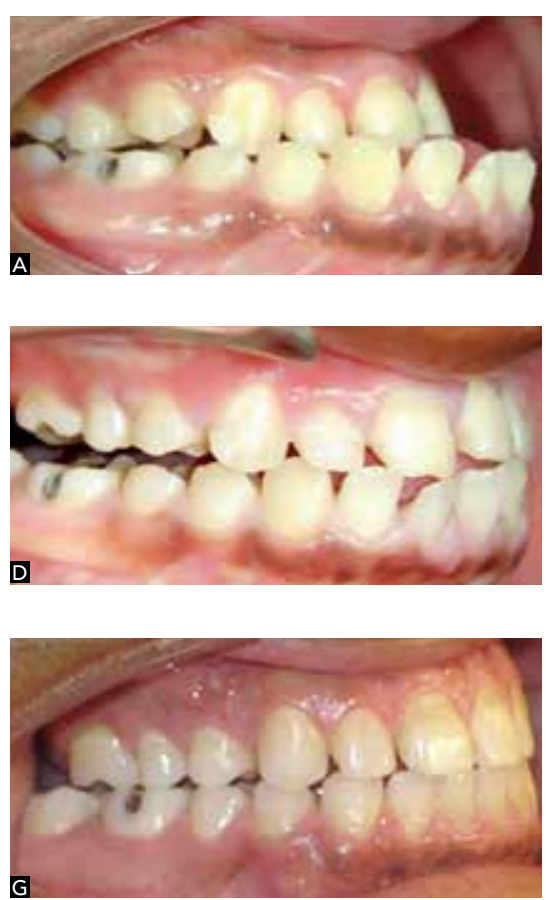

Figure 7 - Intraoral photographs of the patient presented on Figure 6: A, B, C) initial

treatment and orthognathic surgery (Le Fort I and genioplasty).
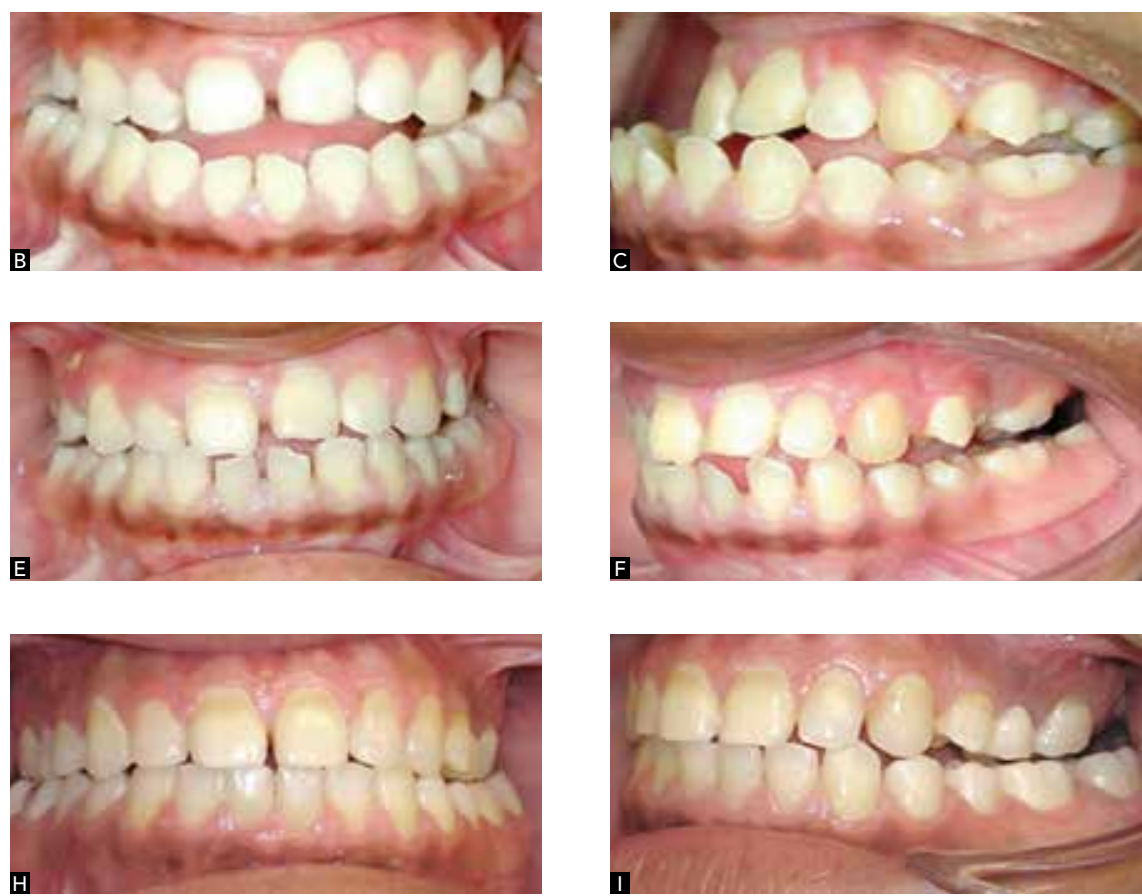
performed in patients that need exclusively maxillary advancement. It is begun with the optional orthodontic preparation followed by the making of the intraoral splint. During surgery, the splint is fixed to the maxillary bone by means of titanium screws. The incision is performed and a classic osteotomy, for the separation in monobloc, ${ }^{20}$ culminating in the complete mobilization of the skeletal segment. The rigid fixation between the frontal bone and the supraorbital protuberances is done by the installation of three titanium plates (Fig 2B). Two lateral plates are for the anchorage of the screws that, in the future, will receive the upper traction pin, which perforate the skin at the eyebrows' level (Fig 2C). After the anchorage of the traction pins, the coronal incision is sutured and the surgeon positions the external cranial halo.

In cases with craniofacial syndromes already surgically treated, it is important to carefully fix the cranial pins, because many patients have cranial defects inherent to the condition or from previous surgery. The halo must be very carefully anchored in solid bone. The anterior part of the halo is positioned 2 to $3 \mathrm{~cm}$ from the forehead - being located in parallel or a little tilted upward in relation to the Frankfurt Horizontal Plane - and from 3 to $6 \mathrm{~cm}$ above the ear lobe. The patient will return 5 to 7 days after surgery and, the distraction device will be installed in a clinical environment with two distraction systems: One upper, at the supraorbital level, by means of traction pins; and one lower, at the dental level, through the external hooks connected with surgical wires to the intraoral splint (Figs 6C, D and E).

The distraction protocol is similar to that applied in patients with only maxillary advancement, in an activation rhythm of 1 to $2 \mathrm{~mm}$ a day, until achieving the correction of the skeletal deformity. The rhythm of distraction may need to be decelerated if the patient presents signs of cerebrospinal fluid leak. The rhythm might also be increased in cases of severe deficiencies, especially in young patients, who have greater healing potential. In cases subjected to monobloc advancement, it is impossible to use the face mask as retention; therefore, it is recommended that the period of consolidation be longer than in patients with cleft, or limited to the moment when the clinician assures the stability of the skeletal segment, by means of clinical, radiographic and tomographic exams.

\section{DISCUSSION}

The standard treatment of patients with dentofacial deformities is orthognathic surgery associated to orthodontic treatment. The surgical procedures of choice for correction of these conditions includes Le Fort I osteotomy, Le Fort III osteotomy, surgically assisted rapid maxillary expansion and sagittal osteotomy of the mandibular ramus; all using rigid fixation techniques.

These approaches often provide successful and predictable correction, however, similar satisfying result is not expected when the technique is performed in patients with a more serious or complex conditions, related to severe maxillary hypoplasia, orofacial clefts and syndromes. ${ }^{31}$

The maxillary advancement in patients without clefts is more stable in the long-term than in patients with clefts. ${ }^{1,7}$ Instead of the radical advancement performed in conventional orthognathic surgeries, the segment will be gradually advanced and the main disadvantages of the rapid advancement will be avoided, that is: The leak of cerebrospinal fluid; the creation of an intracranial space vulnerable to infection; the necessity of massive bone graft and of bone fixation. ${ }^{5}$

In addition, there is limitation on the amount of advancement, dictated by the restrictions of soft tissues, ${ }^{33}$ the radical treatment requires blood transfusion ${ }^{17}$ and at last, the stability in the long-term is questioned. ${ }^{26} \mathrm{On}$ the other hand, the advantages of the gradual advancement of the segment in monobloc include: A stable and predictable advancement of the midface; reduction of the complications, reducing the infections; reduction of the intraoperative and postoperative morbidity; simplification of the procedure; no requirement of bone graft nor rigid fixation; the surgical period is shorter and it also reduces the risk of necessity for blood transfusion.

Both patients with clefts and presenting syndromes, experience stability resulting from treatments with, respectively, advancement of the maxilla and midface (Fig 8). The large amount of bone formation on the pterygomaxillary area is the crucial event that favors this prognosis. Besides the volume, the dense type of lamellar bone - verified in histological and radiographic examination ${ }^{11,16}$ — strengthens the prognosis. This local bone formation also allows additional space for dental eruption (Fig 9). ${ }^{28}$

There is still the possibility of combining the treatment with RED to conventional orthognathic surgery, 

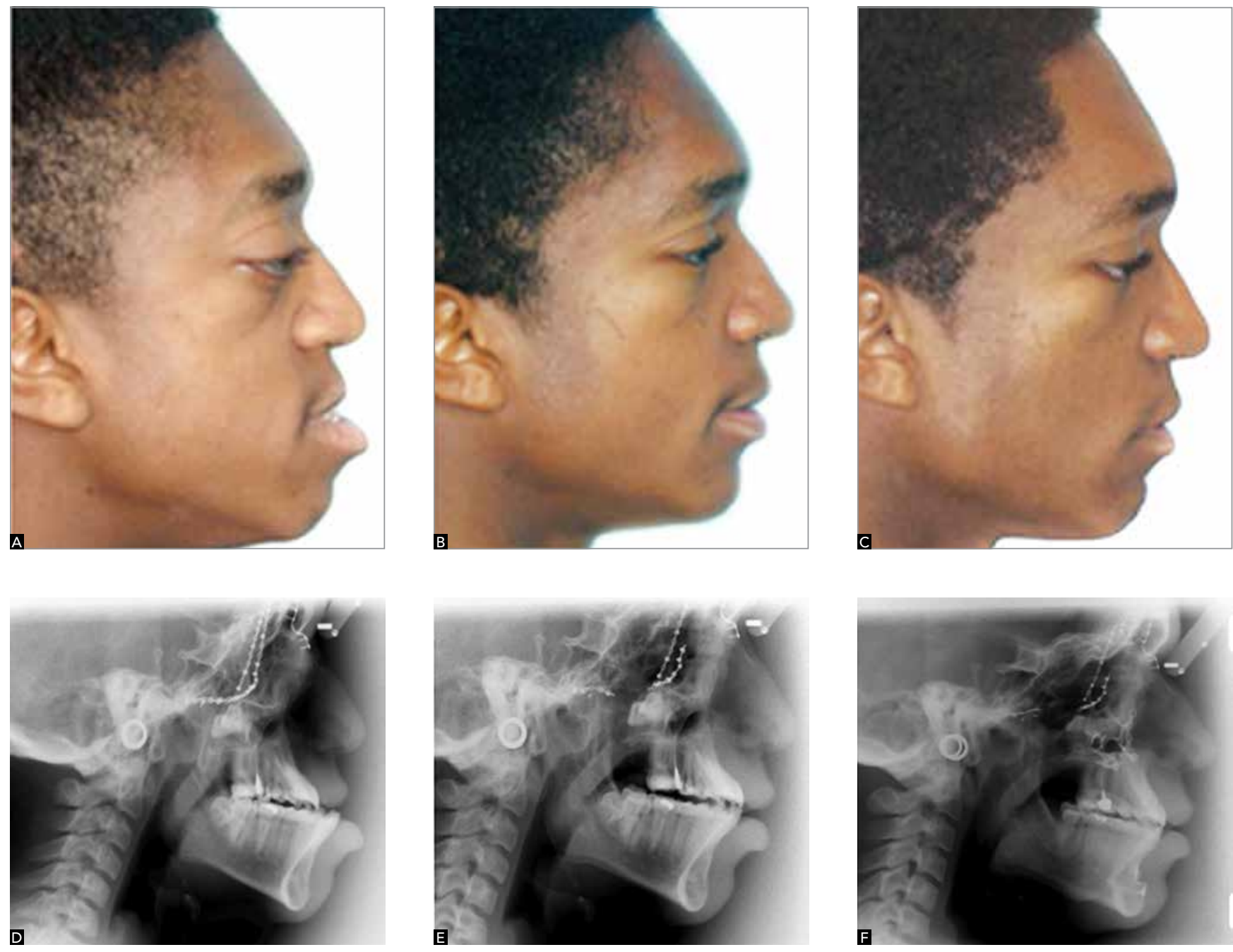

Figure 8 - Photographic and radiographic monitoring of patient with Crouzon syndrome: A, D) initial phase; B, E) final phase, after the distraction osteogenesis C, F) five years of monitoring, after orthodontic treatment and orthognathic surgery (Le Fort I and mentoplasty).
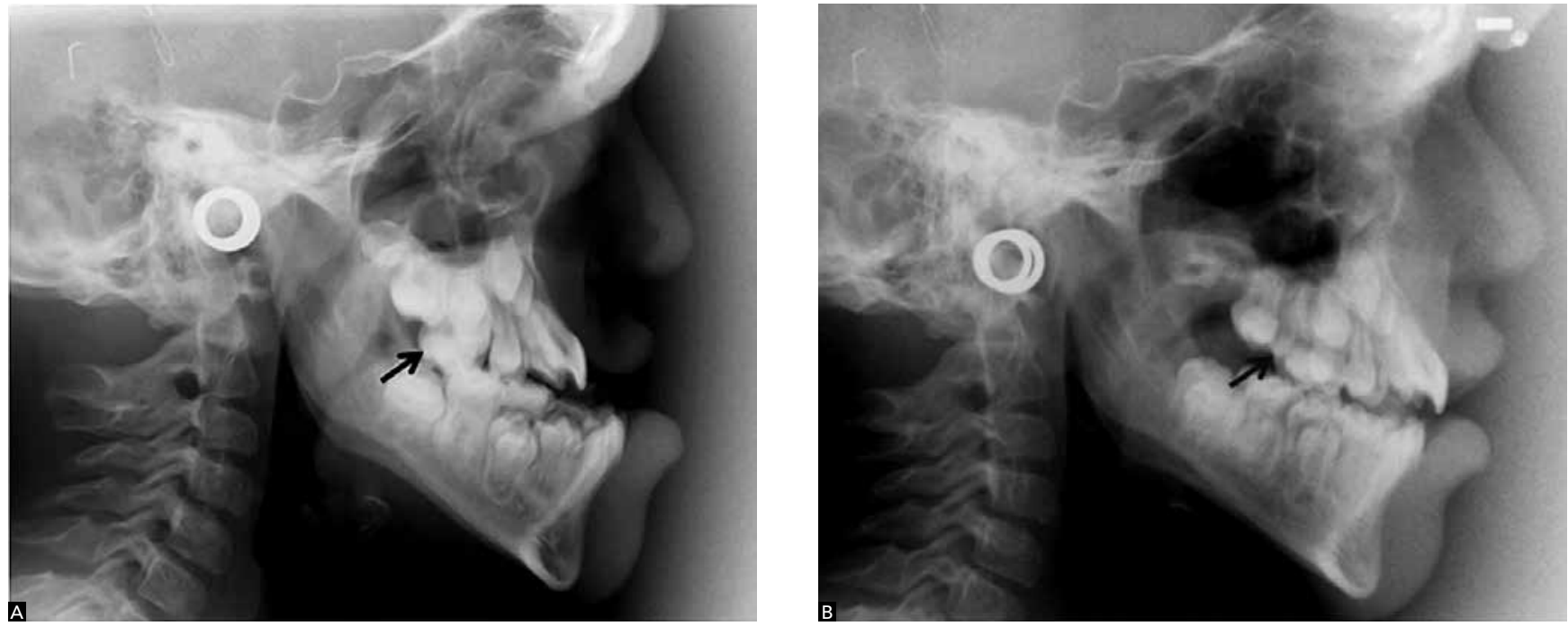

Figure 9 - A) Initial radiograph, before the distraction. B) Radiograph after maxillary advancement, illustrating the gain of space for eruption of the first molar (arrows) 
applied in cases in which only the distraction technique would be insufficient, like some cases in which occurs the limitation of directional movement of the distraction. The benefit of combining these two techniques includes a skeletal correction resulting, mainly, from the distraction technique, followed by a refinement of the positioning of bones and of the occlusion, consequent from the orthognathic surgery; or from the use of osteotomies with simultaneous distraction. ${ }^{32}$

The treatment of patients with maxillary and midface hypoplasia, depending on the distraction osteogenesis technique, involves technical aspects that need more studies to clarify questions related to the individual response to the treatment. Regarding the technique, there are guides for the recommendation of isolated distraction or combined to conventional orthognathic surgery. Other questions are specific to the distraction technique, such as the choice between the use of external or internal distractors for different situations. The internal systems are more interesting, because they are confined; however, there are limitations related to localization, adaptation and degree of advancement. ${ }^{10,24}$

Other considerations, still challenging, include the duration of the consolidation period. It is known that there is direct relation with age, since, on younger patients, this period is shorter. The amount of advancement can also be directly related to the duration of the ideal period of consolidation, which could make the consolidation phase very long and even impracticable. This way, it is vital to obtain a relation of cooperation between clinicians and researchers, to allow the reduction of the consolidation period on the distraction technique. The recent use of morphogenetic proteins, growth factors and low-intensity ultrasound compose the scientific effort for this purpose. ,6, $, 2,25,27,29$ Studies seek to elucidate the response of soft tissues to the gradual movement of the bone in which they are inserted. Some of these changes seem more favorable when using the distraction technique than when using the conventional orthognathic surgery, like the improvement of lips and nose, as consequence of the maxillary advancement. ${ }^{33}$ Besides, a more positive response from the velopharyngeal tissues is noticed when the gradual and radical advancement are compared. ${ }^{13,15}$

\section{FINAL CONSIDERATIONS}

The rigid external distraction technique for advancement of the maxilla and midface, in patients who present clefts, as well as with severe craniofacial syndromes, is secure, predictable and stable. The clinical knowledge available for evaluation allows to recommend the distraction osteogenesis as a treatment technique for conditions which, once, were challenging with the application of traditional surgical techniques. However, the use of the distraction techniques do not exclude the possibility of combining them to traditional surgical techniques. Despite the well-known benefits of the distraction, there are still challenges for its clinical adaptation in patients with clefts and syndromes. This includes the development of new devices, the reduction of the consolidation period and the comprehension of the response of soft tissues to the gradual distraction. 


\section{REFERENCES}

1. Cheung LK, Samman N, Hui E, Tideman H. The 3-dimensional stability of maxillary osteotomies in cleft palate patients. Br J Oral Maxillofac Surg. 1994 Feb;32(1):6-12

2. Ozeç Y, Oztürk M, Kýlýç E, Yeler H, Göze F, Gümüș C. Effect of recombinant human bone morphogenetic protein-2 on mandibular distraction osteogenesis. J Craniofac Surg. 2006:17(1):80-3.

3. Denny AD. Distraction osteogenesis in Pierre Robin neonates with airway obstruction. Clin Plast Surg. 2004;31(2):221-9.

4. Denny AD, Talisman R, Hanson PR, Recinos RF. Mandibular distraction osteogenesis in very young patients to correct airway. Plast Reconstr Surg 2001:108(2):302-11

5. Dunaway DJ, Britto JA, Abela C, Evans RD, Jeelani NU. Complications of frontofacial advancement. Childs Nerv Syst. 2012;28(9):1571-6.

6. El-Bialy TH, Royston TJ, Magin RL, Evans CA, Zaki Ael-M, Frizzell LA. The effect of pulsed ultrasound on mandibular distraction. Ann Biomed Eng 2002;30(10):1251-61

7. Erbe M, Stoelinga PJ, Leenen RJ. Long-term results of segmental repositioning of the maxilla in cleft palate patients without previously grafted alveolo-palatal clefts. J Craniomaxillofac Surg. 1996;24(2):109-17

8. Fearon JA. Halo distraction of the Le Fort III in syndromic craniosynostosis a long-term assessment. Plast Reconstr Surg. 2005;115(6):1524-36.

9. Figueroa AA, Polley JW. Management of the severe cleft and syndromic midface hypoplasia. Orthod Craniofac Res. 2007:10(3):167-79.

10. Figueroa AA, Polley JW. Clinical controversies in oral and maxillofacial surgery: Part two. External versus internal distraction osteogenesis for the management of severe maxillary hypoplasia: external distraction. J Oral Maxillofac Surg. 2008;66(12):2598-604.

11. Figueroa AA, Polley JW, Friede H, Ko EW. Long-term skeletal stability after maxillary advancement with distraction. Plast Reconstr Surg. 2004;114(6):1382-92; discussion 1393-4

12. Figueroa AA, Polley JW, Ko EW. Maxillary distraction for the management of cleft maxillary hypoplasia with a rigid external distraction system. Semin Orthod. 1999:5(1):46-51

13. Guyette TW, Polley JW, Figueroa A, Smith BE. Changes in speech following maxillary distraction osteogenesis. Cleft Palate Craniofac J. 2001;38(3):199-205

14. Harada K, Baba Y, Ohyama K, Enomoto S. Maxillary distraction osteogenesis for cleft lip and palate children using an external, adjustable. rigid distraction device: a report of 2 cases. J Oral Maxillofac Surg. 2001;59(12):1492-6

15. Ko EW, Huang CS, Chen YR, Figueroa AA. Cephalometric craniofacial characteristics in patients with temporomandibular joint ankylosis. Chang Gung Med J. 2005:28(7):456-66

16. Kusnoto B, Figueroa AA, Polley JW. Radiographic evaluation of bone formation in the pterygoid region after maxillary distraction with a rigid external distraction (RED) device. J Craniofac Surg. 2001;12(2):109-17; discussion 118

17. Meling TR, Due-Tønnessen BJ, Høgevold HE, Skjelbred P, Arctander K. Monobloc distraction osteogenesis in pediatric patients with severe syndromal craniosynostosis. J Craniofac Surg. 2004;15(6):990-1000; discussion 1001

18. Molina F, Ortiz Monasterio F, de la Paz Aguilar M, Barrera J. Maxillary distraction: aesthetic and functional benefits in cleft lip-palate and prognathic patients during mixed dentition. Plast Reconstr Surg. 1998;101(4):951-63
19. Ortiz Monasterio F. Molina F, Andrade L, Rodriguez C, Sainz Arregui J. Simultaneous mandibular and maxillary distraction in hemifacial microsomia in adults: avoiding occlusal disasters. Plast Reconstr Surg. 1997:100(4):852-61.

20. Ortiz-Monasterio F, del Campo AF, Carrillo A. Advancement of the orbits and the midface in one piece, combined with frontal repositioning, for the correction of Crouzon's deformities. Plast Reconstr Surg. 1978;61(4):507-16.

21. Polley JW, Figueroa AA. Management of severe maxillary deficiency in childhood and adolescence through distraction osteogenesis with an external, adjustable, rigid distraction device. J Craniofac Surg 1997:8(3):181-5; discussion 186

22. Polley JW, Figueroa AA. Rigid external distraction: its application in cleft maxillary deformities. Plast Reconstr Surg. 1998;102(5):1360-72; discussion 1373-4.

23. Polley JW, Figueroa AA, Charbel FT, Berkowitz R, Reisberg D, Cohen M. Monobloc craniomaxillofacial distraction osteogenesis in a newborn with severe craniofacial synostosis: a preliminary report. J Craniofac Surg 1995:6(5):421-3

24. Drew SJ. Maxillary distraction osteogenesis for advancement in cleft patients, internal devices. J Oral Maxillofac Surg. 2008;66:2592-7.

25. Raschke MJ, Bail H, Windhagen HJ, Kolbeck SF, Weiler A, Raun K, et al. Recombinant growth hormone accelerates bone regenerate consolidation in distraction osteogenesis. Bone. 1999:24(2):81-8

26. Saltaji H, Major MP, Alfakir H, Al-Saleh MA, Flores-Mir C. Maxillary advancement with conventional orthognathic surgery in patients with cleft lip and palate: is it a stable technique? J Oral Maxillofac Surg. 2012;70(12):2859-66

27. Saltaji H, Major MP, Altalibi M, Youssef M, Flores-Mir C. Long-term skeletal stability after maxillary advancement with distraction. Angle Orthod. 2012 Nov:82(6):1115-22

28. Sant'Anna EF, Cury-Saramago AA, Figueroa AA, Polley JW. Evaluation of maxillary permanent molars in patients with syndromic craniosynostosis after monobloc osteotomy and midface advancement with rigid externa distraction (RED). Cleft Palate Craniofac J. 2010;47(2):109-15.

29. Sant'Anna EF, Leven RM, Virdi AS, Sumner DR. Effect of low intensity pulsed ultrasound and BMP-2 on rat bone marrow stromal cell gene expression. J Orthop Res. 2005:23(3):646-52

30. Satoh K, Mitsukawa N, Hosaka Y. Dual midfacial distraction osteogenesis: Le Fort III minus I and Le Fort I for syndromic craniosynostosis. Plast Reconstr Surg. 2003:111(3):1019-28.

31. Takigawa Y, Uematsu S, Takada K. Maxillary advancement using distraction osteogenesis with intraoral device. Angle Orthod. 2010;80(6):1165-75.

32. Watanabe K, Kuroda S, Takahashi T, Kijima T, Torikai K, Moriyama K, et al. Segmental distraction osteogenesis with modified LeFort II osteotomy for a patient with craniosynostosis. Am J Orthod Dentofacial Orthop. 2012;142(5):698-709.

33. Wen-Ching Ko E, Figueroa AA, Polley JW. Soft tissue profile changes after maxillary advancement with distraction. J Oral Maxillofac Surg. 2000:58(9):959-69; discussion 969-70. 